\title{
A ZOPACAS como a manifestação de um projeto de construção regional Brasileiro para o Atlântico Sul: uma leitura crítica (1986-2013)
}

\author{
The ZOPACAS as the manifestation of a \\ Brazilian region-building project for the South \\ Atlantic: a critical review (1986-2013)
}

DOI: $10.21530 /$ ci.v15n1.2020.976

Douglas Henrique Novelli ${ }^{1}$

Alexsandro Eugenio Pereira ${ }^{2}$

\section{Resumo}

O artigo insere-se em um conjunto de estudos sobre construção de regiões, entendidas aqui como construtos cognitivos atrelados a projetos políticos, manifestadas por meio do discurso dos atores. Busca verificar a hipótese de que a Zona de Paz e Cooperação do Atlântico Sul (ZOPACAS) foi criada e mantida como um projeto de construção regional brasileiro para o espaço oceânico em questão. É aplicado o método da análise de conteúdo qualitativa a 27 documentos, divididos entre discursos de representantes brasileiros nas Reuniões Ministeriais da ZOPACAS e circulares internas do Ministério das Relações Exteriores Brasileiro, datadas dos anos de 1986 a 2013 e coletados diretamente no Arquivo Histórico do MRE entre os dias 22 e 25 de agosto de 2017. Os dados sugerem que a ZOPACAS de fato se trata da manifestação de um projeto regional brasileiro para o Atlântico Sul, cujo momento de maior relevância ocorreu em sua primeira década, caindo no ostracismo desde então. Embora a retomada da iniciativa em 2007 tenha sinalizado um potencial renascimento do projeto, os dados coletados

1 Doutorando em Ciência Política pela Universidade Federal do Paraná (UFPR) e Mestre em Ciência Política pela mesma instituição. Membro do Núcleo de Pesquisa em Relações Internacionais (NEPRI-UFPR) desde 2016. Bolsista pela Coordenação de Aperfeiçoamento de Pessoal de Nível Superior (CAPES). ORCID: https://orcid. org/0000-0001-6058-5109; email: douglashnovelli@outlook.com

2 Bolsista de Produtividade em Pesquisa do CNPq - Nível 2. Doutor em Ciência Política pela Universidade de São Paulo (USP). Professor Associado dos Programas de Pós-Graduação em Ciência Política e em Políticas Públicas da Universidade Federal do Paraná. Coordenador do Núcleo de Pesquisa em Relações Internacionais (NEPRI/UFPR) e Editor-Chefe da Revista Conjuntura Global. ORCID: https://orcid.org/0000-0002-9613-4702; email: alexsep@uol.com.br

Artigo submetido em 22/07/2019 e aprovado em 13/03/2020. 
sugerem que o espaço oceânico comum continua sendo de baixa relevância no discurso do governo brasileiro, sobretudo se comparado ao seu período áureo.

Palavras-chave: Atlântico Sul; ZOPACAS; Processo de Construção Regional.

\begin{abstract}
This article is inserted next to a set of studies about the building of regions, defined here as cognitive constructs linked to political projects, which are manifested through the discourse of the actors. It seeks to verify the hypothesis that the South Atlantic Peace and Cooperation Zone (ZOPACAS) was created and maintained as a Brazilian region-building project for the oceanic space in question. It is applied the qualitative content analysis method to 27 documents, divided between speeches of Brazilian representatives at the Ministerial Meetings of ZOPACAS and internal circulars of the Brazilian Ministry of Foreign Affairs, dating from 1986 to 2013 and collected directly in the Historical Archive of the Brazilian Ministry of Foreign Affairs, between August 22 and 25, 2017. The data suggest that the ZOPACAS is indeed the manifestation of a Brazilian regional project for the South Atlantic, whose moment of greatest relevance occurred in its first decade, having been ostracized ever since. Although the resumption of the initiative in 2007 signaled a potential rebirth of the project, the data collected suggest that the common oceanic space remains of little relevance in the discourse of the Brazilian government, especially when compared to its golden age.
\end{abstract}

Keywords: South Atlantic; ZOPACAS; Region-building Process.

\title{
Introdução
}

Em seu artigo “A Region-Building Approach to Northern Europe”, publicado em 1994 pela Review of International Studies, Iver Neumann argumenta que a maior parte dos estudos teóricos existentes sobre regiões ignora uma problemática central: as origens do espaço regional. Segundo o autor, "embora [algumas teorias] vejam as regiões como entidades cujo conteúdo e fronteiras estão em processo de mudança [...] a suposição de que a região existe não é questionada. A natureza e a gênese das regiões é tratada como dada” (Neumann 1994, 57, tradução nossa) ${ }^{3}$. Visando responder a lacuna em questão, Neumann propõe a chamada Abordagem de Construção Regional4 que, inspirada nos trabalhos de

3 Texto original: "although it [some theories] focuses on regions as entities whose contents and borders are in a process of change [...] the assumption that the region exists is unchallenged. The nature and genesis of regions is treated as a given".

4 "Region-Building Approach", no original em inglês. 
Anderson (1983) sobre nacionalismos, defende que regiões sejam interpretadas como comunidades imaginadas, cuja existência é precedida por um ator que, como parte de um projeto político, passa a defender uma identidade cronológica e espacial associada a determinado território - a Região - e procura disseminar tal ideia para o maior número de pessoas (Neumann 2003).

Essa lacuna acaba por se refletir nos estudos empíricos sobre o fenômeno regional e, especificamente, nos estudos voltados para a suposta região do Atlântico Sul. Suposta, pois, independente de qual foco seja dado às dinâmicas sul-atlânticas, não são feitos questionamentos sobre a natureza regional do Atlântico Sul ou sua origem como tal ${ }^{5}$. Isto posto, dois trabalhos emergem como exceções, sendo ambos amparados pela base teórica proposta por Neumann e com análises centradas na Zona de Paz e Cooperação do Atlântico Sul (ZOPACAS), a saber: (1) o artigo "O Brasil e a cooperação em defesa: a construção de uma identidade regional no Atlântico Sul”, de Adriana Abdenur e Danilo de Souza Neto, publicado em 2014 na Revista Brasileira de Política Internacional; e (2) a dissertação de Luísa Calvete Portela Barbosa, intitulada "A Zona de Paz e Cooperação do Atlântico Sul (ZOPACAS): Criação, Projeção e Dimensão Político-Estratégica”, apresentada em 2015 no programa de Estudos Estratégicos Internacionais da UFRGS.

No que toca à genealogia do Atlântico Sul enquanto região, o argumento dos trabalhos é semelhante, defendendo que a ZOPACAS é a materialização de um projeto de construção regional brasileiro. Contudo, diferem-se no foco que conferem à questão. Por um lado, Barbosa (2015) desenvolve um estudo cuja ênfase recai especificamente na ZOPACAS, utilizando uma abordagem histórica e entendendo a iniciativa como "a materialização de um discurso, cujo objetivo é [a] busca por autonomia e autodeterminação da região sul-atlântica por parte de seus integrantes" (Barbosa 2015, 16). Por outro, Abdenur e Souza Neto (2014) tem como foco analisar o suposto projeto regional sul-atlântico defendido pelo governo brasileiro, argumentando que o Estado estaria buscando construir um "cinturão de boa vontade" ${ }^{6}$, que permitiria promover "a criação de uma identidade regional sul-atlântica, na qual o Brasil assegura para si uma posição de destaque" (Abdenur e Souza Neto 2014, 6). Assim, os autores argumentam que, embora a ZOPACAS

5 Exemplos incluem trabalhos focados nas dinâmicas de segurança no oceano (Aguilar 2013; Amorim 2013; Flemes and Costa Vaz 2011), políticas do governo brasileiro para promover o interesse pelo Atlântico Sul no nível doméstico (Wiesebron 2013) e os esforços brasileiros para promover a expansão de sua plataforma continental (Costa 2012; Trentini, Novelli, e Breda 2016).

6 Em alusão ao termo utilizado pelo Ministro da Defesa na abertura do II Seminário de Defesa Nacional, realizado na Escola Superior de Guerra em 15 de fevereiro de 2012. 
surja no final da Guerra Fria como uma iniciativa brasileira, é apenas durante os anos 2000 que o Brasil acumula capital econômico e político para fortalecer esse projeto. Nesse sentido, o presente artigo busca dialogar com esse argumento, mas sustenta que a atuação brasileira no Atlântico Sul foi significativa apenas no período de 1986 a 1995, no qual o Brasil conduziu um projeto de construção regional baseado na ZOPACAS. Não se desconsidera a validade do argumento dos autores supracitados, mas pretende-se aqui destacar outro momento histórico no qual a atuação brasileira mostrou-se mais efetiva - pelo menos no que se refere à construção do Atlântico Sul como região nos termos formulados por Neumann.

$\mathrm{O}$ argumento aqui apresentado baseia-se na premissa segundo a qual "regiões são essencialmente um produto de atores políticos e são criadas pelos discursos desses atores sobre a região" (Tassinari 2004, 56, tradução nossa) ${ }^{7}$. Sendo assim, estudos que tratem de investigar a genealogia de determinado espaço regional devem se debruçar sobre os atos de fala produzidos sobre o mesmo. Por essa razão, o artigo investigará a evolução do discurso do governo brasileiro no que toca ao Atlântico Sul e à ZOPACAS, buscando desvendar se a iniciativa de fato se configura como um projeto de construção regional de origem brasileira para o oceano em questão.

Com esse propósito, foi aplicado o método da análise de conteúdo qualitativa a um conjunto de 27 documentos, examinados com o auxílio do software ATLAS. ti, versão 7.5.7. Os documentos em questão se dividem entre discursos de representantes brasileiros nas Reuniões Ministeriais da ZOPACAS e circulares internas do Itamaraty - coletados diretamente no Arquivo Histórico do MRE. Uma estrutura de duas seções foi adotada no desenvolvimento do artigo, além desta introdução e das conclusões finais. A primeira delas apresenta os métodos de coleta, a descrição do corpus e o detalhamento dos métodos de análise empregados, enquanto a segunda expõe os resultados, apresentados em ordem cronológica e subdivididos em cinco grandes períodos percebidos ao longo da análise.

\section{Metodologia}

O corpus da pesquisa é composto por documentos que expressam a visão brasileira sobre o Atlântico Sul dentro do recorte temporal examinado. Sua análise permite entender a posição do MRE sobre os processos históricos e políticos que

7 Texto original: "regions are essentially a product of political actors and are created by actor-generated discourses on the region". 
moldaram as percepções internacionais sobre o Atlântico Sul. O recorte temporal foi definido com base no período de atividade da ZOPACAS, tendo seu marco inicial na criação da iniciativa em 1986 e, como marco final, sua última Reunião Ministerial, ocorrida em 2013 em Montevidéu. Em sua maior parte ${ }^{8}$, estes dados foram coletados pessoalmente no Arquivo Histórico do MRE, entre os dias 22 e 25 de agosto de 2017. A coleta dos mesmos adotou uma postura inclusiva, considerando todos os documentos localizados no arquivo disponível para consulta que mencionassem o Atlântico Sul ou a ZOPACAS.

Serão analisados 27 documentos ao todo, divididos em duas categorias principais: (1) seis discursos de representantes brasileiros proferidos nas Reuniões Ministeriais da ZOPACAS; e (2) documentos e circulares internas do MRE, cujo conteúdo varia entre subsídios para as Reuniões da ZOPACAS, relatos de reuniões e correspondências, estas com destino tanto interno quanto externo ao Ministério. É importante ressaltar que estes dados não abrangem os discursos brasileiros em todas as Reuniões Ministeriais da ZOPACAS, assim como provavelmente não representam todos os documentos produzidos sobre o Atlântico Sul pelo governo brasileiro no período em questão. Os documentos aqui descritos são aqueles aos quais foi possível obter acesso através dos recursos de consulta disponíveis. Embora admitidamente incompletos, eles ainda carregam grande poder explicativo e sua revisão na escala aqui apresentada é inédita.

Os Quadros 1 e 2 detalham a natureza de cada um dos documentos que compõem o corpus da presente pesquisa.

Quadro 1 - Discursos brasileiros nas reuniões ministeriais da ZOPACAS

\begin{tabular}{|l|c|}
\hline \multicolumn{1}{|c|}{ Conteúdo } & Data \\
\hline Draft do discurso do Ministro Brasileiro na I Reunião da ZOPACAS & $25 / 07 / 1988$ \\
\hline Discurso final do Ministro Brasileiro na I Reunião da ZOPACAS & $25 / 07 / 1988$ \\
\hline Discurso e proposta de declaração da ZOPACAS em Reunião Extraordinária & $05 / 10 / 1993$ \\
\hline $\begin{array}{l}\text { Discurso do Ministro Brasileiro na III Reunião da ZOPACAS - Almoço oferecido aos } \\
\text { representantes estatais }\end{array}$ & $21 / 09 / 1994$ \\
\hline Discurso do Ministro Brasileiro na III Reunião da ZOPACAS & $21 / 09 / 1994$ \\
\hline Discurso do Ministro Brasileiro no VII Encontro Ministerial da ZOPACAS & $15 / 01 / 2013$ \\
\hline
\end{tabular}

Fonte: Elaboração própria, com base nos dados coletados no Arquivo Histórico do MRE (2017).

8 Com exceção do discurso do então ministro das Relações Exteriores, Antonio Patriota, por ocasião da VII Reunião ministerial da ZOPACAS, disponível no site do MRE através do link: < http://www.itamaraty.gov.br/ pt-BR/discursos-artigos-e-entrevistas/ministro-das-relacoes-exteriores-discursos/4547-vii-reuniao-ministerialda-zona-de-paz-e-cooperacao-do-atlantico-sul-ZPCAS-texto-base-do-discurso-do-ministro-antonio-de-aguiarpatriota-montevideu-15-de-janeiro-de-2013 > (data de acesso: 26 de junho de 2019). 


\section{Quadro 2 - Documentos internos do Ministério das Relações Exteriores sobre o Atlântico Sul e sobre a ZOPACAS}

\begin{tabular}{|c|c|}
\hline Conteúdo & Data \\
\hline $\begin{array}{l}\text { Carta do Ministro das Relações Exteriores do Brasil ao Secretário Geral das Nações } \\
\text { Unidas }\end{array}$ & $29 / 05 / 1986$ \\
\hline $\begin{array}{l}\text { Circular no 8.669. Nações Unidas XLI Assembleia Geral. Inclusão do Item sobre Zona } \\
\text { de Paz e Cooperação do Atlântico Sul }\end{array}$ & $17 / 06 / 1986$ \\
\hline $\begin{array}{l}\text { ZONA DE PAZ E COOPERAÇÃO DO ATLÂNTICO SUL — Hipóteses para um Programa } \\
\text { de Trabalho }\end{array}$ & - \\
\hline Subsídios prévios à II Reunião da ZOPACAS & 26/04/1989 \\
\hline $\begin{array}{l}\text { Debate sobre a adoção de um tratado específico sobre proteção ambiental no âmbito } \\
\text { da ZOPACAS, envolvendo funcionários do DNU, DOI, DMAE e DTE }\end{array}$ & $04 / 10 / 1989$ \\
\hline Subsídios políticos para II Reunião da ZOPACAS — Namíbia, África do Sul e PALOP & $22 / 05 / 1990$ \\
\hline Subsídios políticos para II Reunião da ZOPACAS — África Ocidental e Central & $31 / 05 / 1990$ \\
\hline Relançamento da ZOPACAS. Expedientes internos mais importantes na área política. & Out/93 \\
\hline $\begin{array}{l}\text { Carta do Ministro Celso Amorim ao Ministro das Relações Exteriores sul-africano, por } \\
\text { ocasião da posse do presidente Nelson Mandela }\end{array}$ & 1994 \\
\hline $\begin{array}{l}\text { Memorandum para chefe da DNU — Zona de Paz e Cooperação no Atlântico Sul: } \\
\text { III Reunião de Estados-membros (preparativos) }\end{array}$ & $13 / 05 / 1994$ \\
\hline III Reunião ZOPACAS: Estimativa de custos com transporte e hospedagem & $15 / 06 / 1994$ \\
\hline $\begin{array}{l}\text { Reunião de Coordenação Brasil-Argentina sobre o III Encontro dos Estados da Zona } \\
\text { de Paz e Cooperação do Atlântico Sul }\end{array}$ & - \\
\hline $\begin{array}{l}\text { Carta do Ministro das Relações Exteriores ao Presidente da República - Submete o } \\
\text { Decreto que designa a Delegação Brasileira para a III reunião da ZOPACAS }\end{array}$ & $15 / 09 / 1994$ \\
\hline IV Reunião Ministerial — Pedido de subsídios & $16 / 07 / 1995$ \\
\hline $\begin{array}{l}\text { Despacho do DOC destinado ao chefe do DPR provendo subsídios para a IV Reunião } \\
\text { da ZOPACAS }\end{array}$ & 02/08/1995 \\
\hline $\begin{array}{l}\text { Comunicação entre o DOI e o SGAP — IV Reunião Ministerial da ZOPACAS: } \\
\text { Necessidades Financeiras }\end{array}$ & $14 / 08 / 1995$ \\
\hline $\begin{array}{l}\text { Comunicação interna entre o DNU e o DOI: IV Reunião da ZOPACAS - Participação } \\
\text { do Brasil }\end{array}$ & $11 / 12 / 1995$ \\
\hline Subsídios Políticos para a IV Reunião da ZOPACAS & $13 / 08 / 1996$ \\
\hline $\begin{array}{l}\text { Subsídios políticos - Comentários sobre a iniciativa Capacetes Brancos da Argentina } \\
\text { no contexto da ZOPACAS }\end{array}$ & $19 / 10 / 1998$ \\
\hline $\begin{array}{l}\text { Ata de reunião: Workshop on the Zone of Peace and Cooperation of the South } \\
\text { Atlantic -Montevideo } 11 \text { to } 13 \text { April } 2007\end{array}$ & $13 / 04 / 2007$ \\
\hline $\begin{array}{l}\text { Ata de reunião: Workshop on the Zone of Peace and Cooperation of the South } \\
\text { Atlantic - Buenos Aires 7, } 8 \text { and } 9 \text { May } 2007\end{array}$ & $07 / 05 / 2007$ \\
\hline
\end{tabular}

Fonte: Elaboração própria, com base nos dados coletados no Arquivo Histórico do MRE (2017). 
Uma vez definido o corpus, foi iniciado o estudo dos documentos, aplicando o método da análise de conteúdo em sua forma qualitativa. Essencialmente, a análise de conteúdo pode ser entendida como um conjunto especifico de procedimentos que buscam, através da manipulação das mensagens presentes nos documentos, colocar em evidência indicadores que revelem os sentidos contidos nos documentos em questão, possibilitando através destes estabelecer inferências (Bardin 2011; Campos 2004; Oliveira 2008; Berelson 1952). Em seu modelo qualitativo, a análise de conteúdo trata-se de "uma forma interpretativa de análise preocupada com descobrir significados, motivos e propósitos no conteúdo textual" (Halperin e Heath 2012, 310, tradução nossa) ${ }^{9}$.

Conforme apontado por Halperin e Heath (2012), a aplicação das técnicas de análise de conteúdo pode ser sumarizada em quatro passos básicos, sendo eles: (1) definir os documentos que irão compor o corpus da pesquisa; (2) estabelecer as variáveis que serão analisadas e as possíveis categorias dentro delas; (3) definir quais unidades de registro serão empregadas; e (4) criar um sistema de marcação que permita identificar e sinalizar no texto a presença e as relações entre as unidades de registro procuradas.

O primeiro destes passos já foi parcialmente coberto com a apresentação dos dados que compõem o corpus da pesquisa - documentos coletados no Arquivo Histórico do MRE, compostos sobretudo de comunicações internas entre funcionários do Ministério, e discursos de representantes brasileiros nas Reuniões Ministeriais da ZOPACAS - , juntamente com as estratégias de coleta empregadas.

Em relação ao processo de categorização, este pode ser descrito como um processo de redução e agrupamento dos textos trabalhados com base em seus conteúdos significativos (Cavalcante, Calixto, e Kerr Pinheiro 2014). Segundo Bardin (2011), o objetivo primordial da categorização é fornecer uma representação simplificada dos dados trabalhados, os quais são agrupados em categorias, isto é, classes que reúnem um grupo de elementos sob um título genérico, aqui identificados como "unidades de registro" (que nada mais são do que os segmentos ou partes do texto que serão submetidos ao processo de categorização), tendo como base características que estes elementos apresentam em comum. É através destas categorias que os dados trabalhados exprimem seus significados, os quais guiam a análise (Campos 2004).

9 Texto original: "Qualitative content analysis is a more interpretive form of analysis concerned with uncovering meanings, motives, and purposes in textual content”. 
A presente pesquisa adotará unidades de registro de nível semântico, baseadas em temas, que nada mais são do que "a unidade de significação que se liberta naturalmente de um texto analisado segundo certos critérios relativos à teoria que serve de guia à leitura" (Bardin 2011, 135). Serão identificadas nos discursos manifestações que apresentem correspondência com seis variáveis analíticas estabelecidas a priori, as quais guiarão a análise dos textos observados. As seis variáveis empregadas são: (1) manifestações sobre a identidade regional do Atlântico Sul e que associem essa identidade regional à ZOPACAS; (2) elementos empregados para justificar a natureza do Atlântico Sul enquanto uma região; (3) pautas balizadoras da ZOPACAS enquanto um projeto de cooperação; (4) desafios percebidos; (5) resultados das estratégias adotadas; e (6) demais atores apontados como relevantes pelos interlocutores brasileiros cujo discurso será analisado.

Halperin e Heath (2012) ainda sugerem a adoção de um sistema de marcação capaz de ajudar o pesquisador no processo de categorização das unidades de registro buscadas no texto. Optou-se por empregar o software ATLAS.ti, versão 7.5.7, específico para a análise de dados em pesquisas qualitativas. O software em questão permite a análise conjunta de um amplo volume de documentos e, embora o corpus da presente pesquisa seja limitado a arquivos de texto, o programa ainda suporta arquivos de imagem, áudio, vídeo e de informações geoespaciais. Dentro dele, as categorias de análise são traduzidas como codes, com cada code funcionando como uma etiqueta, demarcando e agrupando em suas respectivas categorias as parcelas do texto que se mostram relevantes para a análise. Essa função facilita visualizar as unidades de registro nas quais cada categoria está presente, assim como identificar os pontos nos quais verifica-se a coocorrência de duas ou mais categorias, com uma sendo utilizada para justificar a presença de outra, por exemplo. O software ainda oferece uma função de mapa de rede, que permite estabelecer relações entre categorias distintas conforme essas relações emergem da leitura dos documentos analisados. Em conjunto, essas funções tornam o ATLAS.ti um instrumento metodológico ideal para auxiliar na aplicação do método da análise de conteúdo em pesquisas como a aqui apresentada.

Esclarecidos os aspectos metodológicos que guiaram a pesquisa, avança-se agora para a análise dos dados e a discussão dos resultados obtidos. 


\section{Análise e apresentação dos resultados}

A análise a seguir será de teor qualitativo, aprofundando-se no conteúdo dos textos analisados, e sua apresentação será realizada por ordem cronológica, visando observar como a narrativa brasileira sobre o Atlântico Sul evoluiu nesses documentos. No material em questão, foi possível observar cinco grandes períodos: (1) do surgimento da ZOPACAS em 1986 até sua I Reunião Ministerial, em 1988; (2) um período de fortalecimento da iniciativa entre os anos de 1989 e 1990; (3) um período marcado pela superação ou quase-superação das principais pautas políticas da Zona, o que demandou uma atualização de seus objetivos para tentar preservar sua relevância, ocorrido entre os anos de 1993 e 1994; (4) o fracasso do projeto de atualização seguido de progressivo abandono da ZOPACAS, entre 1995 e 1998; e (5) a retomada da iniciativa, a partir de $2007^{10}$.

\section{Das origens da ZOPACAS até a I Reunião (1986-1988)}

Conceitualmente, a ZOPACAS tem suas origens como uma resposta ao projeto da Organização do Tratado do Atlântico Sul (OTAS), então defendida pelos governos norte-americano, sul-africano e pelos governos militares uruguaio e argentino. A ideia do OTAS existia desde a década de 1950, porém ganhou força apenas na década de 1970 com a independência angolana e a subsequente ascensão ao poder do Movimento Popular de Libertação de Angola (MPLA) que, apoiado pela União Soviética, produziu o temor que as dinâmicas usualmente pacíficas do Atlântico Sul fossem sobrepostas pelas dinâmicas globais conflituosas das duas grandes potências (Hurrell 1983).

Embora ciente da delicada situação geopolítica criada pelo avanço da influência soviética no continente africano, o governo brasileiro não via com bons olhos o projeto, considerando-o com potencial de danificar ainda mais as relações entre o Ocidente e a África. Ademais, como aponta Bandeira (1999), desde a Crise do Petróleo de 1973 o Brasil havia se afastado de sua política de alinhamento automático com os EUA, flexibilizando a retórica anticomunista de sua política externa ao passo que se aproximava dos Estados africanos, sendo, inclusive, o primeiro Estado a reconhecer a independência angolana.

10 Os anos de 1991, 1992 e entre 1999 e 2006 parecem ter representado períodos de inatividade da ZOPACAS, nos quais não foi possível localizar quaisquer documentos no arquivo histórico do MRE. 
Nesse sentido, o diplomata e então conselheiro do MRE, José Viegas Filho, ainda em 1982 advoga a favor de um arranjo regional para o Atlântico Sul produzido pelos próprios Estados por ele banhados, marcado por relações horizontais entre seus membros e que manteve o Atlântico Sul fora das dinâmicas de confrontação entre as duas superpotências:

O Atlântico Sul deve ser percebido através de uma ótica centrada no relacionamento intrarregional, de natureza horizontal e de sentido Sul-Sul, e não vinculada essencialmente à confrontação entre as superpotências. [...] para que isso ocorra é necessário um trabalho político específico no sentido de identificar e implementar os fundamentos da ótica que inspira a política dos países em desenvolvimento da área no que se refere ao espaço que os une (Viegas Filho 2016, 100).

Isto posto, a ideia de criar um arranjo regional para o Atlântico Sul que se opusesse à proposta da OTAS não era nova. Como aponta uma circular interna do MRE, a primeira manifestação pública do desejo do governo brasileiro de promover a iniciativa que evoluiria para a ZOPACAS ocorreu ainda em 1977, durante visita oficial do Ministro da Educação de Cabo-Verde. Na ocasião, foi emitido um comunicado de imprensa conjunto no qual se afirmava "a identidade de ponto-de-vista [...] sobre os interesses dos países ribeirinhos de oceanos comuns em promoverem, na zona oceânica que compartilham, esforços no sentido do desenvolvimento autônomo" (apud Brasil 1986b, para. 4). Ao longo dos anos seguintes, a diplomacia brasileira obteve sucesso em angariar apoiadores à ZOPACAS na costa africana, com a adesão da Guiné, da Guiné Bissau e da República Popular do Congo ao projeto. Todavia, foi apenas após a Guerra das Malvinas (1982) e o fim dos regimes militares na Argentina (1983) e no Uruguai (1985) que o projeto recebeu apoio dos Estados da margem sul-americana do Atlântico.

Assim, no primeiro ano do recorte temporal analisado, foram localizados nos arquivos do MRE dois documentos pertinentes ao tema em questão. O primeiro deles trata exatamente da carta enviada pelo então Ministro das Relações Exteriores brasileiro, Abreu Sodré, ao Secretário Geral da ONU, datada de 29 de maio de 1986, que solicitava a inclusão da ZOPACAS na agenda de debates da $41^{\text {a }}$ reunião da ONU (Brasil 1986a), instrumentalizando questões como a independência da Namíbia e o regime do Apartheid sul-africano para solicitar apoio internacional à iniciativa brasileira de tornar o Atlântico Sul uma zona de paz. Logo no início, há uma declaração sobre a natureza regional do Atlântico Sul, definido como uma 
"região com identidade própria”, com seus Estados "compartilhando problemas e interesses semelhantes" (Brasil 1986a, 1, tradução nossa) ${ }^{11}$. Essa correspondência corrobora, ao menos em um primeiro momento, com a hipótese de que o Brasil atuou como principal region-builder no Atlântico Sul, sendo seu projeto regional em grande medida associado à proposição da ZOPACAS.

Foi possível também obter acesso a uma circular interna do MRE do ano de 1986, a qual também cita a independência da Namíbia, o regime do Apartheid e a situação política na Angola como pontos de interesse que demandam uma maior atenção do governo brasileiro para com o Atlântico Sul (Brasil 1986b). Esse texto estabelece a Nigéria como principal parceiro no Atlântico Sul e: “(1) define o Atlântico Sul como região, com identidade específica; (2) estabelece o caráter afro-latino-americano dessa região" (Brasil 1986b, 3). Sugere ainda que os arranjos objetivados para o oceano fariam parte de um projeto maior, o qual, "somando-se ao Tratado da Bacia do Prata e ao Tratado de Cooperação Amazônica, fecharia o círculo de entendimentos em torno da região em que o Brasil está inserido" (Brasil 1986b, 4-5), reforçando o caráter securitário do projeto regional sul-atlântico.

O próximo documento localizado trata de um conjunto de subsídios que antecedem a I Reunião Ministerial da ZOPACAS. Esse documento se inicia constatando a natureza dual da ZOPACAS em sua origem, focando prioritariamente em duas vertentes distintas, ainda que vistas como interligadas, sendo elas a cooperação para a paz e a cooperação para o desenvolvimento (Brasil 1988a). No que toca à cooperação para a paz, o documento cita o desejo de manter o Atlântico Sul como uma zona livre de armas nucleares e ingerências externas, assim como as instabilidades causadas pelo regime do Apartheid na África do Sul. Sugere, ainda, a criação de um banco de dados sobre recursos oceanográficos compartilhado entre os países sul-atlânticos.

Esses elementos também estão presentes no discurso pronunciado pelo Ministro das Relações Exteriores na inauguração da I Reunião Ministerial da ZOPACAS, o qual, além de defender a ideia do projeto regional baseado em duas frentes, uma de cooperação para paz e outra de cooperação para o desenvolvimento, também ressalta conexões históricas e culturais que ligam o Brasil e demais Estados ribeirinhos ao Oceano Atlântico e uns aos outros, clamando que tornem "patente a consciência de que pertencemos à região sul-atlântica" (Brasil 1988b, 6). O Atlântico Sul é assim tratado como diretamente associado à ZOPACAS, sendo seu

11 Texto Original: "region with an identity of its own [...] sharing similar problems and interests". 
surgimento visto como o "momento em que nossa região assume sua identidade própria” (Brasil 1988b, 2).

\section{Fortalecimento da iniciativa (1989-1990)}

O período entre a I Reunião e a II Reunião Ministerial da ZOPACAS (1988 e 1990, respectivamente) foi marcado pelo fortalecimento da iniciativa no cenário internacional e pelo avanço de várias das pautas que originalmente estavam no centro da agenda da Zona. Contudo, ao mesmo tempo cresciam as crises políticas e econômicas em vários de seus Estados-membros na costa africana.

Dois documentos foram localizados remetendo ao ano de 1989. O primeiro deles tem caráter informativo, resumindo os debates correntes e dando subsídios aos trabalhos futuros. Esse texto se destaca por apresentar, de forma resumida, as linhas gerais do projeto regional então perseguido e propagado pelo governo brasileiro. Os elementos essenciais da iniciativa seriam:

(a) a definição do Atlântico Sul como região com identidade específica;

(b) a afirmação do caráter afro-latino-americano dessa região;

(c) o reconhecimento da responsabilidade especial dos países da área sobre o oceano;

(d) a ênfase na ideia de cooperação regional - preservação do meio ambiente, aproveitamento dos recursos oceânicos, entre outros campos;

(e) o interesse em neutralizar as ameaças à paz e à segurança dessa região (Brasil 1989, 7).

Tece ainda comentários sobre a posição argentina, cujo governo teria “acentuado os elementos da ZOPACAS passíveis de utilização como fator de suporte às posições argentinas no contencioso com o Reino Unido” (Brasil 1989, 5) (isto é, a questão das Ilhas Falklands). Embora o governo brasileiro reconheça a legitimidade dessas demandas, aponta que a "forma unidimensional [do governo argentino] de tratar o tema tende a elidir aspectos fundamentais da iniciativa” (Brasil 1989, 5). Sendo o Brasil a principal liderança do processo de construção regional do Atlântico Sul (ao menos nesse momento temporal), sua postura contrária à instrumentalização da ZOPACAS no contencioso das Ilhas Falklands pode ajudar a entender as razões pelas quais o tema apareceu relativamente pouco.

No ano de 1990 foi realizada a II Reunião Ministerial da ZOPACAS, em Abuja, Nigéria. Embora não tenha sido possível obter a transcrição do discurso do Ministro 
das Relações Exteriores brasileiro nesta reunião, foram localizados dois documentos elaborados com o objetivo de fornecer subsídios para a mesma. O primeiro destes documentos (Brasil 1990a) trata do novo cenário político com a independência da Namíbia e relativo declínio do regime do Apartheid sul-africano. No tocante a Namíbia, trata da instabilidade política do país após sua independência, sobretudo no que se refere aos problemas sociais, econômicos e relacionados às tensões raciais, enxergando no encontro da ZOPACAS uma primeira oportunidade para estabelecer parcerias políticas e econômicas junto ao novo governo. Já a África do Sul é apresentada como um dos prováveis pontos centrais a serem debatidos na Reunião de Abuja, com o MRE identificando avanços lentos no desmantelamento do regime do Apartheid, ao passo que demonstra preocupação com o aumento da violência nas ruas do país. Defende, portanto, o reconhecimento das medidas positivas em conjunto com a manutenção das sanções.

O segundo documento tem a mesma natureza, objetivando fornecer subsídios para a vindoura reunião, mas foca na crise política na qual vários países da África Ocidental se encontravam, com protestos populares sendo "impelidos por dificuldades econômicas, [pelo] descontentamento com o sistema de partido único e o clamor pelo multipartidarismo" (Brasil 1990b, 1) ${ }^{12}$. O documento traz uma análise favorável à postura brasileira de privilegiar a cooperação técnica "sem tentativas de cultivar hegemonias nem de ensinar o caminho a terceiros" (Brasil 1990b, 6), levantando a hipótese de que no futuro a ZOPACAS poderia servir como uma plataforma funcional para coordenação de projetos de cooperação multilateral entre os Estados da região.

\section{Exaustão de pautas e o projeto de aggiornamento (1993-1994)}

No ano de 1993 foi produzido aquele que é possivelmente o documento mais completo sobre as relações políticas referentes ao Atlântico Sul no período. Na realidade, esse arquivo produzido pela Subsecretaria-geral de Assuntos Políticos (SGAP) sob o título de "Relançamento da Zona de Paz e Cooperação do Atlântico Sul (ZOPACAS) - Expedientes Internos Mais Importantes na Área Política” (Brasil 1993a), trata dos principais documentos e memorandos, expedidos por setores do MRE entre novembro de 1992 e outubro de 1993, concernentes ao receio de

12 Especificamente, o documento em questão busca fornecer subsídios sobre a situação no Zaire, Gabão, Nigéria, Senegal, Costa do Marfim e Camarões. 
esvaziamento da ZOPACAS frente à superação de sua agenda política original. Logo em suas primeiras páginas, o então Secretário-Geral e futuro Ministro das Relações Exteriores, Luiz Felipe Lampreia, em memorando destinado a SGAP, reconhece que a ZOPACAS "veio perdendo impulso à medida em que a confrontação ideológica e estratégica deixou de constituir um dos eixos centrais das relações internacionais", assim como "algumas das preocupações centrais da iniciativa a independência da Namíbia e a questão do apartheid na África do Sul, além do conflito angolano - passaram por evoluções positivas ou alcançaram soluções satisfatórias e definitivas" (Brasil 1993a, 1).

Lampreia desenvolve suas considerações a respeito do projeto de "aggiornamento"13 que o governo brasileiro então buscava promover na ZOPACAS, alterando sua ênfase para a proteção e preservação do meio ambiente marinho e com o intuito declarado de prevenir seu esvaziamento, uma vez que suas razões motoras haviam se exaurido ou estavam em vias de ser exauridas. Posteriormente, justifica os esforços em manter a ZOPACAS ativa pelo papel da iniciativa em fortalecer o protagonismo brasileiro na região ao mesmo tempo que enfraquece outros projetos regionais que seriam possivelmente contrários aos interesses brasileiros. Segundo ele:

Essa preocupação com o revigoramento de uma iniciativa brasileira que chegou a ter ampla repercussão, mas perdeu impulso, justifica-se hoje inclusive como forma de oferecer alternativa à ideia, ressuscitada pela Argentina, de uma nova versão do antigo projeto de um Pacto do Atlântico Sul, [...] com uma vertente de segurança em moldes ainda marcados por preocupação estratégica. Paralelamente, e como preocupação de mais longo prazo, a ideia de promover iniciativas de caráter político-diplomático e econômico comercial - nas vertentes da promoção ambiental e do comércio - atende a interesses de longo prazo do Brasil em sua fronteira atlântica, dando ao país um protagonismo discreto, mas fecundo na região (Brasil 1993a, 6).

De modo condizente, o discurso brasileiro na reunião extraordinária de 1993 (Brasil 1993b) girou em torno de quatro grandes pontos: (1) cooperação ambiental, ocupando posição de destaque como primeiro ponto citado; (2) manutenção do Atlântico Sul como zona não nuclear; (3) proposta para o South Atlantic Games,

13 “Aggiornamento" é um termo em italiano que significa "atualização". Optou-se por manter o termo em italiano por este ter sido assim utilizado nos documentos consultados. 
evento esportivo que reuniria atletas de todos os Estados-membros da ZOPACAS; e (4) o oferecimento do Brasil para sediar a III Reunião Ministerial da ZOPACAS. O preâmbulo da proposta de declaração apresentada pelo governo brasileiro é dedicado exclusivamente à questão ambiental, evocando a Convenção das Nações Unidas sobre o Direito do Mar (ONU 1982), ao passo que argumenta pela necessidade de institucionalizar a proteção e gerenciamento dos recursos costais e marinhos.

Os desdobramentos do ano seguinte confirmaram o diagnóstico desfavorável para a ZOPACAS feito pelo governo brasileiro meses antes. Se o fim do conflito ideológico entre EUA e URSS levantou a necessidade de atualização da pauta política da iniciativa à médio prazo, o ano de 1994 representou a mudança final do cenário no qual a ZOPACAS havia inicialmente sido concebida, tendo o regime do Apartheid chegado ao fim e Nelson Mandela sido eleito presidente da África do Sul. Nesse contexto, o então ministro das Relações Exteriores, Celso Amorim, enviou uma carta ao ministro das Relações Exteriores do novo governo sul africano, ressaltando as "afinidades geográficas, étnicas, históricas e culturais” (Brasil 1994a, 2, tradução nossa) ${ }^{14}$ e convidando a África do Sul a participar da III Reunião Ministerial da ZOPACAS, que aconteceria naquele ano em Brasília, propondo-se a advogar pela imediata admissão do país como membro da ZOPACAS. Essa correspondência marca o momento em que a África do Sul deixa de ser tratada como uma problemática e passa a ser vista como potencial aliada do projeto regional brasileiro.

Os esforços descritos nesses documentos finalmente culminaram na III Reunião Ministerial da ZOPACAS, realizada em 1994 em Brasília. O discurso proferido pelo então Ministro das Relações Exteriores destaca o papel da Nigéria como coordenadora da ZOPACAS nos anos anteriores e, frente ao fim do regime do Apartheid, propõe a adesão imediata da África do Sul como membro pleno da Zona. Seu ponto de maior relevância é a defesa da "transcendência histórica" da ZOPACAS. Nas palavras do Ministro, "da mesma forma que [a ZOPACAS] busca seu elo de continuidade nas raízes comuns de nossos povos, realimenta-se com os influxos externos da atualidade” (Brasil 1994b, 3). Reconhece assim a mudança do cenário político no qual a ZOPACAS se insere, responsável pela exaustão de várias das principais pautas que compunham a agenda política da iniciativa, mas fundamenta a manutenção da Zona ao introduzir novas pautas no debate ao

14 Texto original: "geographical, ethnic, historical and cultural affinities". 
mesmo tempo que busca resgatar antigos temas ainda cabíveis no então cenário, nomeadamente, "a Preservação do Atlântico, [...] a Desnuclearização de nossa região e [...] a Cooperação empresarial” (Brasil 1994b, 8).

\section{Falência da agenda política e abandono da iniciativa (1995-1998)}

Se os documentos observados nos anos de 1993 e 1994 indicavam a preocupação com o futuro da ZOPACAS, os documentos localizados no ano de 1995 revelam um cenário ainda mais desanimador sob a perspectiva do Itamaraty, com os arquivos do MRE indicando um crescente descrédito da iniciativa, tanto entre os outros Estados-membros quanto entre outros órgãos do próprio governo brasileiro. Especificamente, o primeiro desses documentos trata de uma solicitação de subsídios emitida pelo então chefe do DOI, José Bustani, na qual este reconhece os desafios tanto internos quanto externos à continuidade da iniciativa. Segundo ele,

O Brasil, além de divulgar as ZOPACAS nas Nações Unidas, vem trabalhando para a retomada do momentum da iniciativa, que se viu afetada, nos últimos anos, por certa indiferença demonstrada pela Argentina no tratado da matéria e pela conjuntura econômica adversa atravessada por muitos países da costa Atlântica da África [...]. No entanto, muitos dos compromissos assumidos não puderam ser implementados pelo Brasil, em razão de impeditivos de ordem financeira e, mesmo, da falta de interesse de alguns setores do Governo (Brasil 1995a, 1).

Pouco depois revela uma informação interessante: o governo norte-americano estaria disposto a copatrocinar uma Reunião da ZOPACAS para tratar da questão do tráfico de drogas, arcando com os custos da promoção do evento. Nesse sentido, Bustani aponta que, apesar da questão ser uma das preocupações debatidas no âmbito da ZOPACAS, "é preciso estar atento para evitar que o tema do narcotráfico domine e, até mesmo, ofusque os demais objetivos da Zona” (Brasil 1995a, 2). É relevante lembrar que os EUA foram o único Estado a votar contra a Resolução 41/11 da AGNU, responsável por instituir a ZOPACAS (ONU 1986), tendo igualmente votado contra ou se abstido em todas as votações concernentes à iniciativa. Isto posto, é no mínimo curioso o interesse norte-americano em patrocinar um encontro da Zona, sobretudo focado em uma pauta até então tratada como secundária por seus Estados-membros.

O segundo dos documentos localizados no ano de 1995 registra uma comunicação emitida pelo Departamento de Operações de Promoção Comercial 
(DOC) e destinada ao chefe do Departamento de Promoção Comercial e Investimentos (DPR) ${ }^{15}$. Pela natureza dos departamentos envolvidos, não surpreende o caráter puramente econômico do texto, focando nos aspectos da cooperação comercial no âmbito da ZOPACAS. O texto desenvolve o argumento de que a ZOPACAS poderia servir como canal de cooperação para a superação da crise econômica dos Estados-membros através da identificação de áreas prioritárias, reconhecendo, contudo, o grande desafio em buscar "um meio termo entre as necessidades dos Países-Membros com uma linha de industrialização já definida [...] e outros países com atividades econômicas ainda incipientes" (Brasil 1995b, 2-5).

O terceiro documento localizado no ano de 1995 em muito se assemelha ao primeiro, sendo também assinado por Bustani, no qual relata sua "preocupação com os parcos resultados obtidos pelo Governo brasileiro na projeção universal dos propósitos da Zona do Atlântico Sul” (Brasil 1995c, 1). Segundo ele, os resultados mais positivos atingidos até então se concentravam na arena da paz e segurança que, por suas metas geralmente declaratórias, são mais facilmente atingidas. Por outro lado, as demais vertentes de atuação da ZOPACAS apresentavam resultados muito abaixo do esperado, tendo em vista a falta de interesse dos demais órgãos do governo e da comunidade empresarial. A cooperação esportiva surge como exemplo emblemático: a Reunião dos Ministros dos Esportes, vista como uma das metas prioritárias para os países africanos membros da iniciativa, acordada durante a III Reunião Ministerial e prevista para o início de 1995, não havia se concretizado até agosto daquele ano, momento no qual o DOI emitia o comunicado aqui analisado. O cancelamento de Reuniões Ministeriais também se tornaria prática recorrente na ZOPACAS desse momento em diante. A título de exemplo, o discurso proferido pelo representante da Namíbia durante a $49^{a}$ Sessão da AGNU (ONU 1994) indica que o cronograma inicial para as reuniões futuras era a realização da IV Reunião em 1995, na África do Sul; da V Reunião em 1996, na Argentina; e da VI em 1997, no Benin. As Reuniões sediadas pela África do Sul e pela Argentina acabaram só ocorrendo em 1996 e 1998, respectivamente. Já a VI Reunião, após vários cancelamentos, acabou sendo transferida para Angola, ocorrendo apenas no ano de 2007.

O último documento localizado no ano de 1995, um memorando produzido pelo DNU, ecoa as preocupações expressas pelo chefe do DOI, apontando a falta de financiamento e "a existência de regimes políticos em situação delicada perante

15 Nota-se que o DOC é uma subdivisão do DPR. 
a comunidade internacional (notadamente o da Nigéria)" (Brasil 1995d, 2) como principais desafios para a cooperação econômica e comercial objetivada pelo governo brasileiro através da ZOPACAS. Ressalta ainda a aparente improdutividade da III Reunião Ministerial da ZOPACAS, realizada em Brasília no ano anterior, afirmando que

Os compromissos assumidos durante a IIIa. Reunião Ministerial da ZOPACAS em 1994 ainda não proporcionaram os resultados esperados. [...] A IVa. Reunião Ministerial foi adiada para os dias 1 e 2 de abril de 1996, na expectativa de que algo de concreto possa ser executado pelos países-membros da ZOPACAS até a realização da nova reunião (Brasil 1995d, 2).

Esses apontamentos são particularmente relevantes, pois, como o próprio documento em questão aponta, o Brasil era visto como "o principal patrocinador da ZOPACAS na comunidade internacional” (Brasil 1995d, 3). Assim, o projeto regional brasileiro para o Atlântico Sul estava intimamente ligado à iniciativa da ZOPACAS, a qual, com a exaustão de sua agenda política original e fracasso em garantir apoio após sua reformulação de pauta, parecia então fadada ao fracasso.

No ano de 1996 foi localizado apenas um arquivo, que, de modo geral, não fornece informações novas, reforçando apenas o caráter de cooperação econômica e ambiental pelo qual a pauta da ZOPACAS se tracejava, ao mesmo tempo que reafirma os "impeditivos de ordem financeira, econômica e política que permeiam o assunto" (Brasil 1996, 3). A partir desse ponto, o volume de documentos localizados nos arquivos do MRE se torna notavelmente escasso. Entre os anos de 1996 e 2007, foi possível localizar apenas um único documento com menção ao tema da ZOPACAS, datado de 1998. Nele, a ZOPACAS aparece como um tema secundário, abordado dentro do contexto das atividades de assistência humanitária promovidas pela ONU (Brasil 1998).

Apesar de ser possível - e até mesmo provável - que tenham existido outros debates internos entre funcionários do MRE, cujos registros não foram possíveis de serem acessados através dos arquivos disponíveis para consulta, a escassez de documentos e registros disponíveis está em concordância com o próprio período de inatividade sofrido pela ZOPACAS entre 1998 e 2007, ano no qual finalmente ocorreu a VI Reunião Ministerial da Zona em Luanda, Angola. 


\section{Retomada da ZOPACAS (2007-2013)}

Mesmo com o reavivamento da ZOPACAS em 2007, o volume de documentos disponível para consulta se manteve escasso. Não foi possível, por exemplo, obter acesso ao discurso do representante brasileiro durante a VI Reunião. Na realidade, os dois documentos do ano de 2007 cujo acesso foi possível diferem notavelmente daqueles analisados até aqui: ambos são atas de workshops realizados a título de preparação para a VI Reunião.

O primeiro destes documentos se refere a uma reunião realizada entre os dias 11 e 13 de abril de 2007 em Montevidéu, Uruguai. No relato, observa-se a reafirmação das conexões históricas e culturais que ligam as duas regiões costais do Atlântico Sul e comentários gerais sobre a cooperação para o desenvolvimento, retratada como intrinsecamente ligada às questões de paz e segurança. O que mais desperta a atenção são os debates sobre o combate ao crime organizado, principalmente ligado ao tráfico de drogas e armas de pequeno porte, tema que outrora ocupava posição secundária no âmbito da ZOPACAS, mas aqui ocupa 11 dos 28 tópicos da ata (ZOPACAS 2007a, paras. 10-20). A natureza do segundo documento é mais limitada, referindo-se a uma reunião realizada entre os dias 07 e 09 de maio de 2007 em Buenos Aires, cujo conteúdo majoritariamente trata da gestão cooperativa dos recursos do mar, sobretudo em relação à pesca no Atlântico Sul (ZOPACAS 2007b).

O último documento disponível é o discurso do então Ministro das Relações Exteriores, Antonio Patriota, durante a VII e última Reunião Ministerial da ZOPACAS, realizada em 2013 na cidade de Montevidéu. Nele, o ministro reconhece o papel de "liderança e contribuição significativa" do governo angolano para a revitalização da Zona (Brasil 2013, para. 2) e reafirma a agenda de trabalho da ZOPACAS como atuante em três frentes: (1) desarmamento e não-proliferação; (2) cooperação; e (3) temas econômicos (Brasil 2013, para. 18). No que toca às relações econômico-estratégicas, dá especial ênfase nas questões "relativas ao aproveitamento de riquezas energéticas e ao elevado potencial do Atlântico Sul para o desenvolvimento socioeconômico dos países costeiros, assim como à preocupação de sustentabilidade e racionalidade na utilização dos recursos marinhos" (Brasil 2013, para. 25). Finalmente, reafirma o caráter regional do Atlântico Sul, afirmando que a VII Reunião Ministerial da Zona comprovava “o compromisso dos países africanos e sul-americanos com a identidade sul-atlântica” (Brasil 2013, para. 4) e que "temos [os Estados-membros da ZOPACAS] nossa identidade própria como região, estamos conscientes dela, e dela nos orgulhamos” (Brasil 2013, para. 48). 


\section{Conclusões}

A análise dos documentos revelou uma narrativa consistente da forma como os círculos internos do MRE viam o Atlântico Sul e a postura dos principais atores regionais. Segundo essa narrativa, a ZOPACAS seria originalmente um projeto de construção regional brasileiro, que já nasce propagando a ideia do Atlântico Sul ser "uma região com identidade própria”, com seus Estados "compartilhando problemas e interesses" (Brasil, 1986a, p. 1, tradução nossa) ${ }^{16}$.

Em seus primeiros anos, a agenda política da ZOPACAS foi um produto direto da época em que foi criada: embora sempre tenha buscado tratar de projetos de cooperação para o desenvolvimento socioeconômico, as maiores preocupações eram diretamente associadas à percepção de ameaça oriunda da confrontação entre as duas superpotências e do regime sul-africano que, além de institucionalizar políticas discriminatórias contra seus próprios cidadãos, ocupava ilegalmente o território da Namíbia, influenciava abertamente a Guerra Civil Angolana e perseguia um programa nuclear para fins militares, o qual ia diretamente contra a ideia de uma Zona de Paz livre de armas nucleares no Atlântico Sul.

Com o fim da Guerra Fria e do regime do Apartheid sul-africano, a ZOPACAS viu a exaustão de suas pautas principais, correndo o risco de avançar rapidamente rumo à irrelevância. Esse cenário foi notado ainda em 1992 por representantes brasileiros que, visando recuperar o projeto regional de iniciativa brasileira (e que, portanto, posicionava o Brasil no centro político do Atlântico Sul), lançaram o projeto de "aggiornamento" da Zona, o qual, entre outras medidas, propunha a inclusão da pauta de proteção do meio ambiente marinho como meio de mantê-la como um fórum relevante internacionalmente.

Apesar de sua aceitação, essas pautas acabaram por não produzir o engajamento esperado por parte dos Estados-membros da ZOPACAS. Embora fossem até certo ponto aceitas como relevantes, os Estados careciam da capacidade financeira para o devido engajamento, visto que vários deles, sobretudo na costa africana, passavam por crises financeiras e políticas. Ainda pior: sendo a ZOPACAS uma iniciativa brasileira, esperava-se que o Brasil estivesse disposto a arcar com os custos dessa liderança. Porém, como o então chefe do DOI descreve, "muitos dos compromissos assumidos não puderam ser implementados pelo Brasil, em razão de impeditivos de ordem financeira e, mesmo, da falta de interesse de alguns

16 Texto Original: "region with an identity of its own [...] sharing similar problems and interests". 
setores do Governo" (Brasil, 1995c, p. 1). O resultado dificilmente poderia ter sido outro: entre os anos de 1995 e 2007, a iniciativa da ZOPACAS pouco a pouco caminhou rumo à inatividade e ao esquecimento.

Em grande medida, o estudo aqui apresentado dialoga com o argumento de Abdenur e Souza Neto (2014), segundo o qual, no período que compreende os governos Lula e Rousseff, o governo brasileiro atuou como region-builder no Atlântico Sul ao promover a ideia de um "cinturão de boa vontade" em seu entorno estratégico, objetivando criar uma identidade regional sul-atlântica que assegurasse para si posição de destaque na política regional. Através da análise dos dados obtidos, é possível concluir que esse argumento pode ser complementado com uma leitura apurada de outros momentos históricos nos quais a atuação do governo brasileiro como region-builder mostrou-se até mais significativa para o desenvolvimento da experiência específica da ZOPACAS.

Embora o Brasil tenha demonstrado certo grau de atividade enquanto regionbuilder no período indicado por Abdenur e Souza Neto (2014), ressalta-se que isso ocorreu apenas após a revitalização da ZOPACAS, iniciada no ano de 2007, sendo esta revitalização iniciada não pelo Brasil, mas por Angola. Ademais, os esforços brasileiros no período em questão também foram lentos e precários, esbarrando em dificuldades financeiras que limitaram a atuação brasileira no âmbito da ZOPACAS, em contraste com os que foram executados pelo governo brasileiro até 1995. Não há dúvida de que a ZOPACAS é a manifestação de um projeto regional orquestrado pelo governo brasileiro, mas, da mesma forma, os dados analisados apontam que este projeto só foi perseguido com verdadeiro afinco durante a primeira década da iniciativa (1986-1995) e não mais tarde, quando se tentou revitalizar a ZOPACAS.

\section{Referências}

Abdenur, Adriana Erthal, e Danilo Marcondes de Souza Neto. 2014. "O Brasil e a Cooperação Em Defesa: A Construção de Uma Identidade Regional No Atlântico Sul." Revista Brasileira de Politica Internacional 57 (1): 5-21. < https://doi.org/ 10.1590/0034-7329201400101 > .

Aguilar, Luiz Cruz. 2013. "Atlântico Sul: As Relações Do Brasil Com Os Países Africanos No Campo Da Segurança e Defesa.” Austral: Revista Brasileira de Estratégia e Relações Internacionais 2 (4): 49-71. 
Amorim, Sérgio Gonçalves de. 2013. "Perspectivas Brasileiras Na Convergência Entre o SISBIN e a ZOPACAS.” Austral: Revista Brasileira de Estratégia e Relações Internacionais 2 (4): 11-31.

Anderson, Benedict. 1983. Imagined Communities: Reflections on the Origin and Spread of Nationalism. Verso. Revised. Londres: Verso.

Bandeira, Luiz Alberto Moniz. 1999. Relações Brasil - EUA No Contexto Da Globalização. II - Rivalidade Emergente. 2nd ed. São Paulo: Editora SENAC.

Barbosa, Luísa Calvete Portela. 2015. “A Zona de Paz e Cooperação Do Atlântico Sul (ZOPACAS): Criação, Projeção e Dimensão Político-Estratégica.” Dissertação de Mestrado, Programa de Pós-Graduação em Estudos Estratégicos Internacionais, Faculdade de Ciências Econômicas da Universidade Federal do Rio Grande do Sul.

Bardin, Lawrence. 2011. Análise de Conteúdo. São Paulo: Edições 70. < https://books. google.com.br/books?id = AFpxPgAACAAJ > .

Berelson, Bernard. 1952. Content Analysis in Communication Research. Society. Nova York: Free Press. < https://doi.org/10.1086/617924 > .

Brasil. 1986a. Carta Do Ministro Das Relações Exteriores Do Brasil Ao Secretário Geral Das Nações Unidas. Brasília: MRE.

Brasil. 1986b. Circular No 8.669. Nações Unidas XLI Assembleia Geral. Inclusão Do Item Sobre Zona de Paz e Cooperação Do Atlântico Sul. Brasília: MRE.

Brasil. 1988a. Zona de Paz e Cooperação do Atlântico Sul: Hipóteses para um Programa de Trabalho. Brasília: MRE.

Brasil. 1988b. Discurso Final Do Ministro Brasileiro Na $1^{a}$ Reunião Da ZOPACAS. Rio de Janeiro: MRE.

Brasil. 1989. Subsídios Prévios à $2^{a}$ Reunião Da ZPCAS. Brasília: MRE.Brasil. 1990a. Subsídios Políticos Para II Reunião Da ZPCAS - Namíbia, África Do Sul e PALOP. Brasília: MRE.

Brasil. 1990b. Subsídios Políticos Para II Reunião Da ZPCAS - África Ocidental e Central. Brasília: MRE.

Brasil. 1993a. Relançamento da Zona de Paz e Cooperação do Atlântico Sul (ZPCAS) Expedientes Internos Mais Importantes na Área Política. Brasília: MRE.

Brasil. 1993b. Discurso e Proposta de Declaração Da ZOPACAS Em Reunião Extraordinária. Nova York: MRE.

Brasil. 1994a. Carta Do Ministro Celso Amorim Ao Ministro Das Relações Exteriores Sul-Africano, Por Ocasião Da Posse Do Presidente Nelson Mandela. MRE.

Brasil. 1994b. Discurso Do Ministro Brasileiro Na $3^{a}$ Reunião Da ZOPACAS. Brasília: MRE.

Brasil. 1995a. IVa Reunião Ministerial — Pedido de Subsídios. Brasília: MRE.

Brasil. 1995b. Despacho do DOC Destinado ao Chefe do DPR Provendo Subsídios Para a IV Reunião Da ZPCAS. Brasília: 
Brasil. 1995c. Comunicação Entre o DOI e o SGAP - IVa Reunião Ministerial Da ZPCAS: Necessidades Financeiras. Brasília: MRE.

Brasil. 1995d. Comunicação Interna Entre o DNU e o DOI: IV Reunião Da ZPCAS — Participação Do Brasil. Brasília: MRE.

Brasil. 1996. Subsídios Políticos Enviados Para a Embaixada Brasileira Em Pretória. Brasília: MRE.

Brasil. 1998. Subsídios Políticos - Comentários Sobre a Iniciativa Capacetes Brancos Da Argentina No Contexto Da ZOPACAS e de Atividades de Assistência Humanitária No Contexto Das Nações Unidas. Brasília: MRE.

Barbosa, Luísa Calvete Portela. 2013. Texto-Base Do Discurso Do Ministro Antonio de Aguiar Patriota Por Ocasião Da VII Reunião Ministerial Da ZOPACAS. Brasília: MRE. < http://www.itamaraty.gov.br/pt-BR/discursos-artigos-e-entrevistas/ministrodas-relacoes-exteriores-discursos/4547-vii-reuniao-ministerial-da-zona-de-paz-ecooperacao-do-atlantico-sul-zopacas-texto-base-do-discurso-do-ministro-antoniode-aguiar-patriota-mo > .

Campos, CJG. 2004. "Método de Análise de Conteúdo: Ferramenta Para a Análise de Dados Qualitativos No Campo Da Saúde.” Rev Bras Enferm Brasília 57 (5): 611-14. https://doi.org/10.1590/S0034-71672004000500019.

Cavalcante, Ricardo Bezerra, Pedro Calixto, e Marta Macedo Kerr Pinheiro. 2014. “Análise de Conteúdo: Considerações Gerais, Relações Com a Pergunta de Pesquisa, Possibilidades e Limitações Do Método.” Informacao e Sociedade 24 (1): 13-18.

Costa, Wanderley Messias da. 2012. "Projeção Do Brasil No Atlântico Aul: Geopolítica e Estratégia.” Revista USP, no. 95: 9-22.

Flemes, Daniel, e Alcides Costa Vaz. 2011. “Security Policies of India, Brazil and South Africa: Regional Security Contexts as Constraints for a Common Agenda." GIGA WP, no. 160: 25. < https://doi.org/10.12957/rmi.2014.10863 > .

Halperin, Sandra, e Oliver Heath. 2012. Political Research - Methods and Practical Skills. Oxford: Oxford University Press.

Hurrell, Andrew. 1983. “The Politics of South Atlantic Security: A Survey of Proposals for a South Atlantic Treaty Organization." Royal Institute of International Affairs 1944- 59 (2): 179-93.

Neumann, Iver B. 1994. “A Region-Building Approach to Northern Europe.” Review of International Studies 20 (1): 53-74.

Neumann, Iver B. 2003. “A Region-Building Approach.” In Theories of New Regionalism, edited by Fredrik Söderbaum and Timothy M. Shaw. Londres: Palgrave Macmillan.

Oliveira, Denize Cristina. 2008. “Análise de Conteúdo Temático-Categorial: Uma Proposta de Sistematização.” Revista de Enfermagem UFRJ 16 (4): 569-76. 
ONU. 1982. “Convenção Das Nações Unidas Sobre o Direito Do Mar.” 1982. < http://www. icmbio.gov.br/cepsul/images/stories/legislacao/Decretos/1995/dec_1530_1995_ convencaonacoesunidassobredireitomar.pdf $>$.

ONU. 1986. "Resolution A/RES/41/11: Declaration of a Zone of Peace and Co-Operation of the South Atlantic.” Voting Record - General Assembly. < https://digitallibrary. un.org/record $/ 280823 ? \ln =$ en $>$.

ONU. 1994. “General Assembly Official Records, 49th Session : 74th Meeting.” United Nations Digital Library. 1994. < https://digitallibrary.un.org/record/167685? ln = en > .

Tassinari, Fabrizio. 2004. "Mare Europaeum: Baltic Sea Region Security and Cooperation from Post-Wall to Post-Enlargement Europe.” Tese de Doutorado, Department of Political Science, University of Copenhagen.

Trentini, Bruno, Douglas Novelli, e Juliana Breda. 2016. “A Aplicação de Políticas Públicas Na Busca Pela Ampliação Da Plataforma Continental Brasileira: Resultados e Desafios.” Revista Brasileira de Políticas Públicas e Internacionais 1 (2).

Viegas Filho, José. 2016. A Segurança Do Atlântico Sul e as Relações Com a África. Brasília: FUNAG.

Wiesebron, Marianne. 2013. “Amazônia Azul: Pensando a Defesa Do Território Marítimo.” Austral: Revista Brasileira de Estratégia e Relações Internacionais 2 (3): 107-31.

ZOPACAS. 2007a. Workshop on the Zone of Peace and Cooperation of the South Atlantic - Montevideo 11 to 13 April 2007.

ZOPACAS. 2007b. Workshop on the Zone of Peace and Cooperation of the South Atlantic - Buenos Aires 7, 8 and 9 May 2007. 